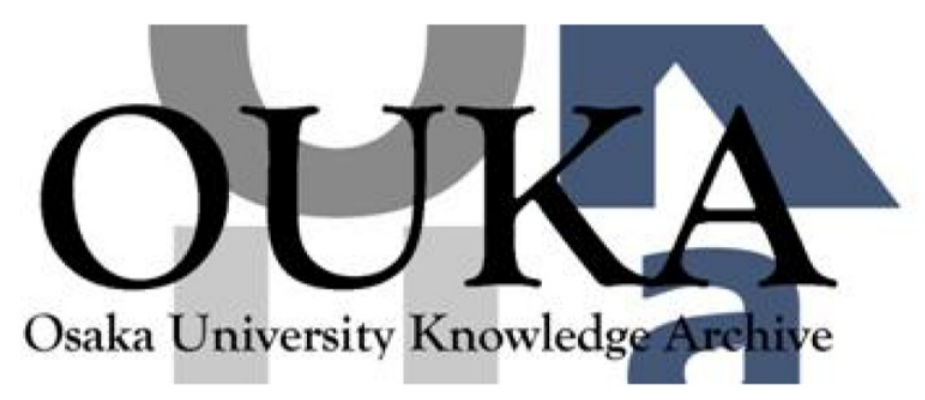

\begin{tabular}{|c|l|}
\hline Title & $\begin{array}{l}\text { Thermodynamic Relationship between the Enthalpy } \\
\text { Interaction Parameter and Entropy Interaction } \\
\text { Parameter in Liquid Iron-Nitrogen Based Ternary } \\
\text { Alloys }\end{array}$ \\
\hline Author(s) & $\begin{array}{l}\text { Tanaka, Toshihiro; Gokcen, Nev . A. ; Iida, } \\
\text { Takamichi et al. }\end{array}$ \\
\hline Citation & Zeitschrift für Metallkunde. 85(10) p. 696-p. 700 \\
\hline Issue Date & 1994 \\
\hline oaire:version & VoR \\
\hline URL & https://hdl. handle. net/11094/26513 \\
\hline rights & oCarl Hanser Verlag, München \\
\hline Note & \\
\hline
\end{tabular}

Osaka University Knowledge Archive : OUKA

https://ir. Library. osaka-u. ac. jp/

Osaka University 
Toshihiro Tanaka, Nev A. Gokcen*, Takamichi lida and Zen-ichiro Morita

(Department of Materials Science and Processing, Faculty of Engineering, Osaka University, 2-1 Yamadaoka, Suita, Osaka 565, Japan; * Albany Research Center, U.S. Bureau of Mines, 1450 Queen Avemue SW, Albany, Oregon, 97321-2198, U.S.A.)

\section{Thermodynamic Relationship between the Enthalpy Interaction Parameter and the Entropy Interaction Parameter in Liquid Iron-Nitrogen Based Ternary Alloys}

\begin{abstract}
A statistical thermodynamic solution model based on the free volume theory is applied to liquid iron-nitrogen based ternary alloys to derive the relationship between the enthalpy interaction parameter and the entropy interaction parameter. A linear relationship between those parameters is obtained. Then, Wagner's interaction parameters of nitrogen with some metallic elements in liquid iron alloys are evaluated. These results show that the free volume of the solute elements is an important factor to determine the excess entropy terms in those alloys.
\end{abstract}

\section{Introduction}

In previous works [ 1 to 7$]$, the authors explained the thermodynamic relationship between the enthalpy of mixing, $\Delta H_{\mathrm{MIx}}$, and the excess entropy, $\Delta S^{\mathrm{Ex}}$, between the partial enthalpy of solution, $\bar{H}_{X}$, and the partial excess entropy $\bar{S}_{X}^{\mathrm{Ex}}$, in liquid binary alloys, and between the enthalpy interaction parameter $\eta_{X}^{Y}$ and the entropy interaction parameter $\sigma_{X}^{Y}$ in liquid ternary dilute alloys $(X, Y$ : solute elements) by a statistical thermodynamic solution model based on the free volume theory. Using this model, we evaluated the excess entropy and the excess Gibbs energy of solutions when enthalpy terms were given. Richardson [8] described that there exists a linear relationship between $\eta_{X}^{Y}$ and Wagner's interaction parameter $\varepsilon_{X}^{Y}$ in liquid ironnitrogen based ternary alloys, which means that $\eta_{X}^{Y}$ is proportional to $\sigma_{X}^{Y}$. The ratio of $\eta_{X}^{Y} / \varepsilon_{X}^{Y}$ has been reported to be $7 \mathrm{kcal}$ at $1873 \mathrm{~K}$ in those alloys by Chipman and Corrigan [9]. Although we previously derived the relationship between $\eta_{X}^{Y}$ and $\sigma_{X}^{Y}$ in liquid ternary dilute alloys which consisted of three metallic elements, we could not deal with liquid alloys including gaseous elements such as nitrogen in that derived model. Then, the purpose of the present study is to extend the above free volume solution model to liquid iron-nitrogen based ternary alloys, in which nitrogen dissolves interstitially in the alloys, and to derive the relationship between $\eta_{X}^{Y}$ and $\sigma_{X}^{Y}$.

\section{Derivation of Thermodynamic Equations}

The following derivation of $\varepsilon_{Y}^{Y}$ is based on a theoretical work by Tsu and Saito [10], but we introduce the concept of the free volume into their work. Let us consider an $\mathrm{Fe}-X-\mathrm{N}$ ternary solution, in which $\mathrm{Fe}$ atoms and atoms of the metallic element $X$ occupy substitutional sites and $\mathrm{N}$ atoms dissolve in interstitial sites. The structure of liquid iron alloys is assumed to be similar to the facecentered cubic structure as Tsu and Saito [10], and Foo and Lupis [11] assumed. Then, the number of substitutional lattice points is equal to that of interstitial points. The number of arrangements of $N_{\mathrm{Fe}}$ atoms of $\mathrm{Fe}$ and $N_{X}$ atoms of $X$ on $\left(N_{\mathrm{Fe}}+N_{X}\right)$ substitutional sites is given by

$$
\frac{\left(N_{\mathrm{Fe}}+N_{X}\right) !}{N_{\mathrm{Fe}} ! N_{X} !}
$$

Similarly, the number of arrangements of $N_{\mathrm{N}}$ atoms of $\mathrm{N}$ on $\left(N_{\mathrm{Fe}}+N_{X}\right)$ interstitial sites is given by

$$
\frac{\left(N_{\mathrm{Fe}}+N_{X}\right) !}{N_{\mathrm{N}} !\left(N_{\mathrm{Fe}}+N_{X}-N_{\mathrm{N}}\right) !}
$$

Here, we assume that the atoms of $\mathrm{Fe}, X$ and $\mathrm{N}$ are distributed randomly on their sites. The energy for the above arrangement of atoms is represented by

$$
\begin{aligned}
E= & N_{\mathrm{Fe} X} u_{\mathrm{Fe} X}+N_{\mathrm{FeFe}} u_{\mathrm{FeFe}}+N_{X X} u_{X X}+N_{\mathrm{FeN}} u_{\mathrm{FeN}} \\
& +N_{X \mathrm{~N}} u_{X \mathrm{~N}}+N_{\mathrm{NN}} u_{\mathrm{NN}}
\end{aligned}
$$

where $u_{i j}$ is the pair interaction energy of the $i-j$ pair. $N_{i j}$ $(i, j=\mathrm{Fe}, X$ or $\mathrm{N})$ in Eq. (3), which is the number of $i-j$ pairs, is given as follows

$$
\left.\begin{array}{ll}
N_{\mathrm{Fe} X}=\frac{Z N_{\mathrm{Fe}} N_{X}}{N_{\mathrm{Fe}}+N_{X}} & N_{\mathrm{FeN}}=\frac{Z^{\prime} N_{\mathrm{Fe}} N_{\mathrm{N}}}{N_{\mathrm{Fe}}+N_{X}} \\
N_{\mathrm{FecFe}}=\frac{Z N_{\mathrm{Fe}}^{2}}{2\left(N_{\mathrm{Fe}}+N_{X}\right)} & N_{X \mathrm{~N}}=\frac{Z^{\prime} N_{X} N_{\mathrm{N}}}{N_{\mathrm{Fe}}+N_{X}} \\
N_{X X}=\frac{Z N_{X}^{2}}{2\left(N_{\mathrm{Fe}}+N_{X}\right)} & N_{\mathrm{NN}}=\frac{Z N_{\mathrm{N}}^{2}}{2\left(N_{\mathrm{Fe}}+N_{X}\right)}
\end{array}\right\}
$$

The random configuration of atoms on their sites is assumed in Eq. (4). In the above equations, $Z$ is the number of substitutional nearest-neighbors to a substitutional site or the number of interstitial nearest-neighbors to an interstitial site. $Z^{\prime}$ is the number of substitutional nearest-neighbors to an interstitial site or the number of interstitial nearest-neighbors to a substitutional site. When the free volumes of $\mathrm{Fe}, X$ and $\mathrm{N}$ atoms in the solution are expressed 
as $V_{\mathrm{r}, \mathrm{Fe}}, V_{\mathrm{f}, X}$ and $V_{\mathrm{f}, \mathrm{N}}$, respectively, the partition function of the system is given by

$$
\begin{aligned}
Q= & \frac{\left(N_{\mathrm{Fe}}+N_{X}\right) !}{N_{\mathrm{Fe}} ! N_{X} !} \frac{\left(N_{\mathrm{Fe}}+N_{X}\right) !}{N_{\mathrm{N}} !\left(N_{\mathrm{Fe}}+N_{X}-N_{\mathrm{N}}\right) !} V_{\mathrm{f}, \mathrm{Fe}}^{N_{\mathrm{Fe}}} V_{\mathrm{f}, X}^{N_{X}} V_{\mathrm{t}, \mathrm{N}}^{N_{\mathrm{N}}} \\
& \cdot \exp \left(-\frac{E}{k T}\right)
\end{aligned}
$$

where $k$ is the Boltzmann constant and $T$ is the temperature in $\mathrm{K}$.

The Gibbs energy can be obtained by the following equation

$$
\begin{aligned}
G \approx & -k T \ln Q \\
= & -k T\left\{2\left(N_{\mathrm{Fe}}+N_{X}\right) \ln \left(N_{\mathrm{Fe}}+N_{X}\right)-N_{\mathrm{Fe}} \ln N_{\mathrm{Fe}}\right. \\
& -N_{X} \ln N_{X}-N_{\mathrm{N}} \ln N_{\mathrm{N}} \\
& \left.-\left(N_{\mathrm{Fe}}+N_{X}-N_{\mathrm{N}}\right) \ln \left(N_{\mathrm{Fe}}+N_{X}-N_{\mathrm{N}}\right)\right\} \\
& -k T\left\{N_{\mathrm{Fe}} \ln V_{\mathrm{r}, \mathrm{Fe}}+N_{X} \ln V_{\mathrm{r}, X}+N_{\mathrm{N}} \ln V_{\mathrm{f}, \mathrm{N}}\right\} \\
& +Z u_{\mathrm{Fe} X} \frac{N_{\mathrm{Fe}} N_{X}}{N_{\mathrm{Fe}}+N_{X}}+Z u_{\mathrm{FeFe}} \frac{N_{\mathrm{Fe}}^{2}}{2\left(N_{\mathrm{Fe}}+N_{X}\right)} \\
& +Z u_{X X} \frac{N_{X}^{2}}{2\left(N_{\mathrm{Fe}}+N_{X}\right)}+Z^{\prime} u_{\mathrm{FeN}} \frac{N_{\mathrm{Fe}} N_{\mathrm{N}}}{N_{\mathrm{Fe}}+N_{X}} \\
& +Z^{\prime} u_{X \mathrm{~N}} \frac{N_{X} N_{\mathrm{N}}}{N_{\mathrm{Fe}}+N_{X}}+Z u_{\mathrm{NN}} \frac{N_{\mathrm{N}}^{2}}{2\left(N_{\mathrm{Fe}}+N_{X}\right)}
\end{aligned}
$$

where Stirling's relation $\ln x !=x \ln x-x$ is used.

From Eq. (6), the chemical potential of the solute element $\mathrm{N}$ in liquid iron alloy can be obtained as follows

$$
\begin{aligned}
\mu_{\mathrm{N}}^{\mathrm{L}}= & \frac{\partial G}{\partial N_{\mathrm{N}}} \\
= & k T \ln \left\{\frac{N_{\mathrm{N}}}{\left(N_{\mathrm{Fe}}+N_{X}\right)-N_{\mathrm{N}}}\right\}-k T \ln V_{\mathrm{f}, \mathrm{N}} \\
& +Z^{\prime} u_{\mathrm{FeN}} \frac{N_{\mathrm{Fe}}}{N_{\mathrm{Fe}}+N_{X}}+Z^{\prime} u_{X \mathrm{~N}} \frac{N_{X}}{N_{\mathrm{Fe}}+N_{X}} \\
& +Z u_{\mathrm{NN}} \frac{N_{\mathrm{N}}}{N_{\mathrm{Fe}}+N_{X}} \\
= & k T \ln \left(\frac{x_{\mathrm{N}}}{1-x_{\mathrm{N}}}\right)-k T \ln V_{\mathrm{f}, \mathrm{N}} \\
& +Z^{\prime} u_{\mathrm{FeN}} x_{\mathrm{Fe}}+Z^{\prime} u_{X \mathrm{~N}} x_{X}+Z u_{\mathrm{NN}} x_{\mathrm{N}}
\end{aligned}
$$

where $x_{\mathrm{Fe}}, x_{X}$ and $x_{\mathrm{N}}$ are the mole fractions of $\mathrm{Fe}, X$ and $N$, i.e., $x_{\mathrm{Fe}}=N_{\mathrm{Fe}} /\left(N_{\mathrm{Fe}}+N_{X}+N_{\mathrm{N}}\right) \approx N_{\mathrm{Fe}} /\left(N_{\mathrm{Fe}}+N_{X}\right)$, $x_{X}=N_{X} /\left(N_{\mathrm{Fe}}+N_{X}+N_{\mathrm{N}}\right) \approx N_{X} /\left(N_{\mathrm{Fe}}+N_{X}\right)$, and $x_{\mathrm{N}}=$ $N_{\mathrm{N}} /\left(N_{\mathrm{Fe}}+N_{X}+N_{\mathrm{N}}\right) \approx N_{\mathrm{N}} /\left(N_{\mathrm{Fe}}+N_{X}\right)$. Here, the approximation of $\left(N_{\mathrm{Fe}}+N_{X}+N_{\mathrm{N}}\right) \approx\left(N_{\mathrm{Fe}}+N_{X}\right)$ is used because $N_{\mathrm{N}} \ll\left(N_{\mathrm{re}}+N_{X}\right)$.

The chemical potential of $\mathrm{N}\left(\mathrm{N}_{2}\right.$ gas) in the gas phase is $\mu_{\mathrm{N}}^{\mathrm{G}}=\dot{\mu}_{\mathrm{N}}^{\mathrm{G}}+k T \ln p_{N_{2}}^{1 / 2}$

where $\dot{\mu}_{\mathrm{N}}^{\mathrm{G}}$ is the standard chemical potential of monoatomic N.

From the equilibrium condition $\mu_{\mathrm{N}}^{\mathrm{L}}=\mu_{\mathrm{N}}^{\mathrm{G}}$

$$
\begin{aligned}
\dot{\mu}_{\mathrm{N}}^{\mathrm{G}}+k T \ln p_{\mathrm{N}_{2}}^{1 / 2}= & k T \ln \left(\frac{x_{\mathrm{N}}}{1-x_{\mathrm{N}}}\right)-k T \ln V_{\mathrm{r}, \mathrm{N}} \\
& +\left(Z^{\prime} u_{\mathrm{keN}} x_{\mathrm{rec}}+Z^{\prime} u_{X N} x_{X}+Z u_{\mathrm{NN}} x_{\mathrm{N}}\right)
\end{aligned}
$$

Since $x_{N} \ll 1$, we obtained the following approximations

$$
\begin{aligned}
& \frac{x_{\mathrm{N}}}{1-x_{\mathrm{N}}} \approx x_{\mathrm{N}} \\
& \left(Z^{\prime} u_{\mathrm{reN} N} x_{\mathrm{re}}+Z^{\prime} u_{X \mathrm{~N}} x_{X}\right) \gg Z u_{\mathrm{NN}} x_{\mathrm{N}} \\
& x_{1 \cdot \mathrm{e}} \approx\left(1-x_{X}\right)
\end{aligned}
$$

From Eqs. (9) and (10)

$$
\begin{aligned}
\ln x_{\mathrm{N}}= & \frac{N_{0} \dot{\mu}_{\mathrm{N}}^{\mathrm{G}}}{N_{0} k T}+\ln p_{\mathrm{N} 2}^{1 / 2}+\ln V_{\mathrm{f}, \mathrm{N}} \\
& -\frac{Z^{\prime} u_{\mathrm{FeN}} N_{0}-\left(Z^{\prime} u_{\mathrm{FeN}}-Z^{\prime} u_{X \mathrm{~N}}\right) N_{0} x_{X}}{N_{0} k T} \\
= & \frac{N_{0} \dot{\mu}_{\mathrm{N}}^{\mathrm{G}}}{R T}+\ln p_{\mathrm{N} 2}^{1 / 2}+\ln V_{\mathrm{r}, \mathrm{N}}-\frac{U_{\mathrm{FeN}}-\left(U_{\mathrm{FeN}}-U_{X \mathrm{~N}}\right) x_{X}}{R T}
\end{aligned}
$$

where $U_{\mathrm{FeN}}=Z^{\prime} u_{\mathrm{FeN}} N_{0}$ and $U_{X \mathrm{~N}}=Z^{\prime} u_{X \mathrm{~N}} N_{0}$ and $N_{0}$ is the Avogadro number. $R=N_{0} k$ is the gas constant.

When the infinitely dilute solution is taken as the reference state of the activity of the solute elements, the activity coefficient $f_{\mathrm{N}}=f_{\mathrm{N}}^{N}$ of nitrogen in liquid iron-nitrogen binary alloys becomes unity from Sievert's law. Then, the interaction coefficient $f_{\mathrm{N}}^{X}$ (the effect of the solute element $X$ on the activity coefficient of nitrogen $f_{N}$ ) in liquid iron alloys equilibrated with gas phase of $1 \mathrm{~atm}$ partial pressure of nitrogen is given as follows [10]

$\ln f_{\mathrm{N}}^{X}=\ln x_{\mathrm{N}}(\mathrm{Fe}-\mathrm{N}$ binary $)-\ln x_{\mathrm{N}}(\mathrm{Fe}-X-\mathrm{N}$ ternary) (12) The first term on the right-hand side of Eq. (12) is obtained from Eq. (11) when $x_{X}=0$. Then

$$
\begin{aligned}
\ln f_{\mathrm{N}}^{X}= & \left\{\ln V_{\mathrm{f}, \mathrm{N}}(\mathrm{Fe}-\mathrm{N} \text { binary })-\frac{U_{\mathrm{FeN}}}{R T}\right\} \\
& -\left\{\ln V_{\mathrm{f}, \mathrm{N}}(\mathrm{Fe}-X-\mathrm{N} \text { ternary })\right. \\
& \left.-\frac{U_{\mathrm{FeN}}-\left(U_{\mathrm{FeN}}-U_{X \mathrm{~N}}\right) x_{X}}{R T}\right\} \\
= & \ln \left\{\frac{V_{\mathrm{r}, \mathrm{N}}(\mathrm{Fe}-\mathrm{N} \text { binary })}{V_{\mathrm{r}, \mathrm{N}}(\mathrm{Fe}-X-\mathrm{N} \text { ternary })}\right\}+\frac{\left(U_{X \mathrm{~N}}-U_{\mathrm{FeN}}\right) x_{X}}{R T}
\end{aligned}
$$

where $V_{r, \mathrm{~N}}\left(\mathrm{Fe}-\mathrm{N}\right.$ binary) and $V_{\mathrm{f}, \mathrm{N}}(\mathrm{Fe}-X-\mathrm{N}$ ternary $)$ are the free volumes of the solute element $\mathrm{N}$ in $\mathrm{Fe}-\mathrm{N}$ binary and $\mathrm{Fe}-X-\mathrm{N}$ ternary alloys. These are given by the following equations [1 to 7]

$$
\begin{aligned}
& V_{i, \mathrm{~N}}(\mathrm{Fe}-\mathrm{N} \text { binary })=\left\{-\frac{\pi\left(L_{\mathrm{FeN}}\right)^{2} N_{0} k T}{U_{\mathrm{FeN}}}\right\}^{3 / 2} \\
& V_{\mathrm{r}, \mathrm{N}}(\mathrm{Fe}-X-\mathrm{N} \text { ternary })=\left\{-\frac{\pi\left(L_{\mathrm{Fe} X \mathrm{~N}}\right)^{2} N_{0} k T}{U_{\mathrm{Fe} X \mathrm{~N}}}\right\}^{3 / 2}
\end{aligned}
$$

where $U_{\mathrm{FeN}} / N_{0}\left(=Z^{\prime} u_{\mathrm{FeN}}\right)$ and $U_{\mathrm{Fe} X \mathrm{~N}} / N_{0}$ are the depth of potential energy of the solute element $\mathrm{N}$ in its cell in $\mathrm{Fe}-\mathrm{N}$ binary and $\mathrm{Fe}-X-\mathrm{N}$ ternary alloys in Fig. 1. $L_{\mathrm{FeN}}$ and $L_{\mathrm{Fe} X \mathrm{~N}}$ are the distances which the potential energy of the solute element $\mathrm{N}$ extends in its cell in $\mathrm{Fe}-\mathrm{N}$ binary and $\mathrm{Fe}-X-\mathrm{N}$ ternary alloys in Fig. 1 . Then

$$
\ln \left\{\frac{V_{\mathrm{r}, \mathrm{N}}(\mathrm{Fe}-\mathrm{N} \text { binary })}{V_{\mathrm{t}, \mathrm{N}}(\mathrm{Fe}-X-\mathrm{N} \text { ternary })}\right\}=3 \ln \left(\frac{L_{\mathrm{FeN}}}{L_{\mathrm{Fe}, \mathrm{N}}}\right)+\frac{3}{2} \ln \left(\frac{U_{\mathrm{Fe} X \mathrm{~N}}}{U_{\mathrm{FeN}}}\right)
$$

The second term on the right-hand side of Eq. (16) can be approximated as follows

$$
\begin{aligned}
& \ln \left(\frac{U_{\mathrm{re} X \mathrm{~N}}}{U_{\mathrm{reN}}}\right)=\ln \left(\frac{x_{\mathrm{Fe}} U_{\mathrm{FeN}}+x_{X} U_{\mathrm{xN}}}{U_{\mathrm{FeN}}}\right) \\
& =\ln \left\{\frac{\left(1-x_{X}\right) U_{\mathrm{I} \mathrm{eN}}+x_{X} U_{X \mathrm{~N}}}{U_{\mathrm{I} \in \mathrm{N}}}\right\} \\
& =\ln \left\{\frac{U_{\mathrm{leN}}+\left(U_{X N}-U_{\mathrm{IeN}}\right) x_{X}}{U_{\mathrm{FeN}}}\right\} \\
& =\ln \left(1+\frac{U_{X \mathrm{~N}}-U_{\mathrm{ReN}}}{U_{\mathrm{KiNN}}} x_{X}\right) \\
& \approx \frac{U_{\text {IN }}-U_{1 \mathrm{ieN}}}{U_{\mathrm{IeN}}} x_{X}
\end{aligned}
$$




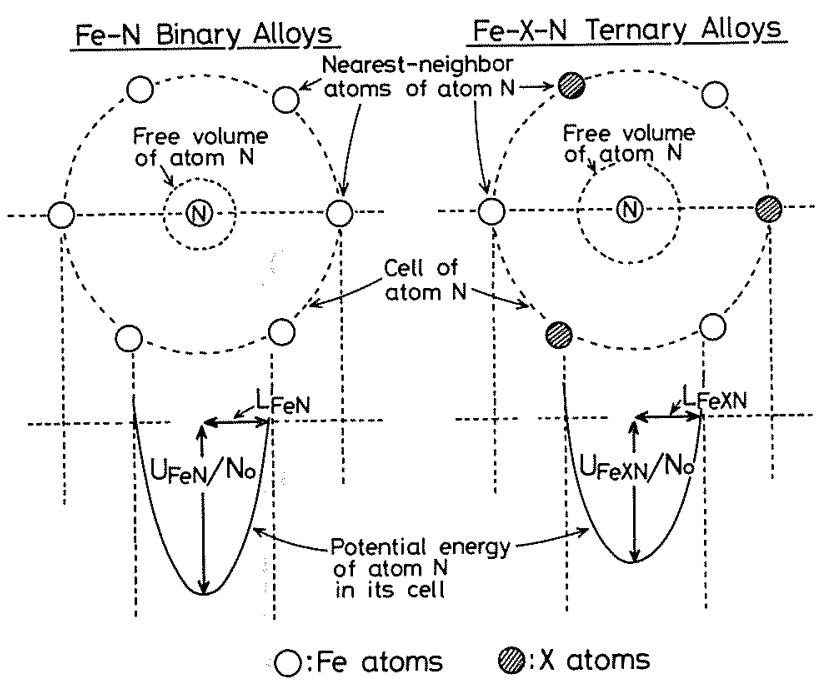

Fig. 1. Schematic diagram of potential energy in a cell of a nitrogen atom in $\mathrm{Fe}-\mathrm{N}$ binary and $\mathrm{Fe}-\mathrm{N}-X$ ternary alloys.

Similarly, the first term in the right-hand side of Eq. (16) can be expressed as follows

$$
\begin{aligned}
\ln \left(\frac{L_{\mathrm{FeN}}}{L_{\mathrm{Fe} X \mathrm{~N}}}\right) & =-\ln \left(\frac{x_{\mathrm{Fe}} L_{\mathrm{FeN}}+x_{X} L_{X \mathrm{~N}}}{L_{\mathrm{FeN}}}\right) \\
& =-\ln \left\{\frac{\left(1-x_{X}\right) L_{\mathrm{FeN}}+x_{X} L_{X \mathrm{~N}}}{L_{\mathrm{FeN}}}\right\} \\
& =-\ln \left(1+\frac{L_{X \mathrm{~N}}-L_{\mathrm{FeN}}}{L_{\mathrm{FeN}}} x_{X}\right) \\
& \approx-\frac{L_{X \mathrm{~N}}-L_{\mathrm{FeN}}}{L_{\mathrm{FeN}}} x_{X}
\end{aligned}
$$

$U_{X \mathrm{~N}} / N_{0}\left(=Z^{\prime} u_{X \mathrm{~N}}\right)$ in Eq. (17) and $L_{X \mathrm{~N}}$ in Eq. (18) are the depth of the potential energy of $N$ in its cell and the distance which the potential energy extends in its cell in $X-\mathrm{N}$ binary alloys. Equations (14) to (18) are based on the assumption that a nitrogen atom in its cell is surrounded by the nearest-neighbor atoms, which consist of only $\mathrm{Fe}$ atoms in $\mathrm{Fe}-\mathrm{N}$ binary alloys, or of $\mathrm{Fe}$ and $X$ atoms in $\mathrm{Fe}-X-\mathrm{N}$ ternary alloys as shown in Fig. 1. From Eqs. (13) to (18)

$$
\begin{aligned}
\ln f_{\mathrm{N}}^{X}= & -3 \frac{L_{X \mathrm{~N}}-L_{\mathrm{FeN}}}{L_{\mathrm{FeN}}} x_{X}+\frac{3}{2} \frac{U_{X \mathrm{~N}}-U_{\mathrm{FeN}}}{U_{\mathrm{FeN}}} x_{X} \\
& +\frac{U_{X \mathrm{~N}}-U_{\mathrm{FeN}}}{R T} x_{X}
\end{aligned}
$$

By differentiating both sides of Eq. (19) with $x_{X}$, the interaction parameter $\varepsilon_{\mathrm{N}}^{X}$ can be obtained as follows

$$
\begin{aligned}
\varepsilon_{\mathrm{N}}^{X} & =\frac{\partial \ln f_{\mathrm{N}}^{X}}{\partial x_{X}} \\
& =-3 \frac{L_{X \mathrm{~N}}-L_{\mathrm{FeN}}}{L_{\mathrm{FeN}}}+\frac{3}{2} \frac{U_{X \mathrm{~N}}-U_{\mathrm{FeN}}}{U_{\mathrm{FeN}}}+\frac{U_{X \mathrm{~N}}-U_{\mathrm{FeN}}}{R T} \\
& =\frac{\left(U_{X \mathrm{~N}}-U_{\mathrm{FeN}}\right)-\left(3 \frac{L_{X \mathrm{~N}}-L_{\mathrm{FeN}}}{L_{\mathrm{FeN}}}-\frac{3}{2} \frac{U_{X \mathrm{~N}}-U_{\mathrm{FeN}}}{U_{\mathrm{FeN}}}\right) R T}{R T} \\
& =\frac{\eta_{\mathrm{N}}^{X}-\sigma_{\mathrm{N}}^{X} T}{R T}
\end{aligned}
$$

where enthalpy interaction parameter $\eta \stackrel{X}{X}$

$\eta_{\mathrm{N}}^{X}=U_{X \mathrm{~N}}-U_{\mathrm{FeN}}$

entropy interaction parameter $\sigma_{N}^{X}$

$\sigma_{\mathrm{N}}^{X}=3 \frac{L_{X \mathrm{~N}}-L_{\mathrm{FeN}}}{L_{\mathrm{FeN}}} R-\frac{3}{2} \frac{U_{X \mathrm{~N}}-U_{\mathrm{FeN}}}{U_{\mathrm{FeN}}} R$

3 Relationship between $\eta_{N}^{X}$ and $\varepsilon_{N}^{X}$, and between $\eta_{N}^{X}$ and $\sigma_{N}^{X}$

In Eq. (22), the following approximation may be applied, as shown numerically later, which shows that the first term with $L$ is much smaller than the second term with $U$ in the excess entropy term,

$3 \frac{L_{X \mathrm{~N}}-L_{\mathrm{FeN}}}{L_{\mathrm{FeN}}} R \ll \frac{3}{2} \frac{U_{X \mathrm{~N}}-U_{\mathrm{FeN}}}{U_{\mathrm{FeN}}} R$

Then, Eq. (22) becomes

$\sigma_{\mathrm{N}}^{X} \approx-\frac{3}{2} \frac{U_{X \mathrm{~N}}-U_{\mathrm{FeN}}}{U_{\mathrm{FeN}}} R$

From Eqs. (20), (21) and (24)

$\frac{\eta_{\mathrm{N}}^{X}}{\varepsilon_{\mathrm{N}}^{X}} \approx \frac{R T}{1+\frac{3 R T}{2 U_{\mathrm{FeN}}}}$
$\frac{\eta_{\mathrm{N}}^{X}}{\sigma_{\mathrm{N}}^{X}} \approx-\frac{2}{3 R} U_{\mathrm{FeN}}$

As shown in Eqs. (25) and (26), the relationships between $\eta_{\mathrm{N}}^{X}$ and $\varepsilon_{\mathrm{N}}^{X}$, and between $\eta_{\mathrm{N}}^{X}$ and $\sigma_{\mathrm{N}}^{X}$ depend on the interaction of the solvent with the gaseous element. Here, we assume that the following relations, which have been used for metallic solutions in the previous work [ 1 to 7], could be applied to the above liquid iron-nitrogen ternary alloys

$$
\left.\begin{array}{l}
U_{\mathrm{FeN}}=\Omega_{\mathrm{FeN}}+\frac{U_{\mathrm{FeFe}}+U_{\mathrm{NN}}}{2}=\Delta H_{\mathrm{N}(\mathrm{Fe})}+\frac{U_{\mathrm{FeFe}}+U_{\mathrm{NN}}}{2} \\
U_{X \mathrm{~N}}=\Omega_{X \mathrm{~N}}+\frac{U_{X X}+U_{\mathrm{NN}}}{2}=\Delta H_{\mathrm{N}(X)}+\frac{U_{X X}+U_{\mathrm{NN}}}{2}
\end{array}\right\}
$$

In the above equations, $\Omega_{\mathrm{FeN}}$ and $\Omega_{X N}$ are interaction energies. $\Delta H_{\mathrm{N}(\mathrm{Fe})}$ and $\Delta H_{\mathrm{N}(X)}$ are the partial enthalpy of solution of $\mathrm{N}$ in $\mathrm{Fe}$ and $X$, respectively. The values of $\Delta H_{\mathrm{N}(\mathrm{Fe})}$ and $\Delta H_{\mathrm{N}(X)}$ are obtained from Miedema's semi-empirical method [12]. From Eq. (27), the term $\left(U_{X N}-U_{\mathrm{FeN}}\right)$ in Eqs. (21) and (22) is written as follows

$$
U_{X \mathrm{~N}}-U_{\mathrm{FeN}}=\left(\Delta H_{\mathrm{N}(X)}-\Delta H_{\mathrm{N}(\mathrm{Fec})}\right)+\left(\frac{U_{X X}-U_{\mathrm{FeFe}}}{2}\right)
$$

In Eq. (28), $U_{\mathrm{FeFe}}$ and $U_{X X}$ can be obtained by [ 1 to 7]

$$
U_{\mathrm{reFc}}=-685 \beta_{\mathrm{Fc}}^{2} T_{\mathrm{m}, \mathrm{Fe}} / \mathrm{J} \mathrm{mol}^{-1}
$$$$
U_{X X}=-685 \beta_{X}^{2} T_{\mathrm{m}, X} / \mathrm{J} \mathrm{mol}^{-1}
$$

where $\beta_{\mathrm{Fc}}$ and $\beta_{X}$ are the ratio of the frequency of an atom in liquid state to that in solid state $[1$ to 7,13$] . T_{\text {m.lic }}$ and $T_{\mathrm{m}, X}$ are the melting points of pure elements $\mathrm{Fe}$ and $X$. We assume that $L_{\mathrm{FeN}}$ and $L_{X \mathrm{~N}}$ in Eq. (22) could be calculated from the following equation

$L_{\mathrm{reN}}=\frac{\left(L_{\mathrm{NN}}+L_{\mathrm{Relic}}\right)}{2} \quad L_{X \mathrm{~N}}=\frac{\left(L_{\mathrm{NN}}+L_{X X}\right)}{2}$ 
Table 1. Physical properties of elements used in the calculation for $\eta \stackrel{X}{N}, \sigma_{N}^{X}$ and $\varepsilon_{N}^{X}$.

\begin{tabular}{|c|c|c|c|c|}
\hline $\begin{array}{c}\text { Element } \\
i\end{array}$ & $\begin{array}{c}\Delta H_{\mathrm{N}(i)} \\
\mathrm{kJ} \mathrm{mol}^{-1}\end{array}$ & $\begin{array}{c}T_{\mathrm{m}, i} \\
\mathrm{~K}\end{array}$ & $\left.\beta_{i}{ }^{\mathrm{a}}\right)$ & $\begin{array}{c}V_{\mathrm{m}, i} \\
\mathrm{~cm}^{3} \mathrm{~mol}\end{array}$ \\
\hline $\mathrm{Co}$ & 28 & 1765 & 0.48 & 6.69 \\
$\mathrm{Cr}$ & -91 & 2178 & 0.50 & 7.23 \\
$\mathrm{Mn}$ & -140 & 1517 & 0.50 & 7.35 \\
$\mathrm{Mo}$ & -91 & 2895 & 0.50 & 9.39 \\
$\mathrm{Ni}$ & 50 & 1728 & 0.47 & 6.60 \\
$\mathrm{~W}$ & -45 & 3655 & 0.50 & 9.55 \\
$\mathrm{Fe}$ & -13 & 1808 & 0.48 & 7.09 \\
$\mathrm{~N}$ & - & - & - & 4.10 \\
\hline
\end{tabular}

$\Delta H_{\mathrm{N}(i)}:$ Ref. [12], $T_{\mathrm{m}, i}$ and $\beta_{i}:$ Ref. [13], $V_{\mathrm{m}, i}=\left(V^{2 / 3}\right)^{3 / 2} ; V^{2 / 3}:$ Ref. [12].

a) When values of $\beta_{i}$ are not available, it can be set approximately to 0.5 [1 to 7$]$.

In the above equation, $L_{\mathrm{NN}}, L_{\mathrm{FeFe}}$ and $L_{X X}$ can be obtained by [1 to 7]

$L_{i i}=\frac{1}{2}\left\{\frac{2^{1 / 2} V_{\mathrm{m} . i}}{N_{0}}\right\}^{1 / 3} \quad(i=\mathrm{Fe}, X$ or $\mathrm{N})$

where $V_{\mathrm{m}, i}$ is the molar volume of pure element $i$.

The values $[12,13]$ of $\Delta H_{\mathrm{N}(i)}, T_{\mathrm{m}, i}, \beta_{i}$ and $V_{\mathrm{m}, i}(i=\mathrm{Fe}$ or $X$ ) in Eqs. (28), (29) and (31) are listed in Table 1. From Eq. (25), the ratio of $\eta_{N}^{X}$ to $\varepsilon_{\mathrm{N}}^{X}$ can be obtained when the value of $U_{\mathrm{FeN}}$ is known. According to Miedema, the energy change $\Delta E$ for the reaction $1 / 2 \mathrm{~N}_{2} \rightarrow \mathrm{N}$ (metal), which means that the gaseous nitrogen becomes the hypothetical metallic monoatomic element, was reported to be 240 [14, $15]$ to 310 [12] $\mathrm{kJ} \mathrm{mol}^{-1}$. We therefore assume, that $U_{\mathrm{NN}}$, the hypothetical binding energy of nitrogen in pure metallic state in Eq. (27), has the similar value as $\Delta E$, and that
$U_{\mathrm{NN}}=215 \mathrm{~kJ} \mathrm{~mol}^{-1}$. Then, from Eqs. (25), (27) and (29), we obtain the ratio $\eta_{\mathrm{N}}^{X} / \varepsilon_{\mathrm{N}}^{X}($ at $1873 \mathrm{~K}) \approx 29 \mathrm{~kJ}(\approx 7 \mathrm{kcal})$, which corresponds to the value reported by Chipman and Corrigan [9]. The calculated results for $\eta_{N}^{X}, \sigma_{N}^{X}$ and $\varepsilon_{N}^{X}$ at $1873 \mathrm{~K}$ obtained from Eqs. (20) to (22) and (27) to (31) using $U_{\mathrm{NN}}=215 \mathrm{~kJ} \mathrm{~mol}^{-1}$ are shown in Table 2, and Figs. 2 and 3. Table 2 shows that the assumption in Eq. (23) is reasonable for liquid iron-nitrogen ternary alloys. As shown in Fig. 2, there exists a linear relationship between $\eta_{\mathrm{N}}^{X}$ and $\varepsilon_{\mathrm{N}}^{X}$ with a slope of $29 \mathrm{~kJ}$. Figure 3 shows that $\eta_{\mathrm{N}}^{X}$ is proportional to $\sigma_{N}^{X}$, and that $\eta_{N}^{X}$ has the same sign as $\sigma_{N}^{X}$, as Richardson [8] pointed out. The approximation, e.g. Eqs. (17) and (18), used in the derivation of the equations in the present model can be applied only to alloy systems with small values of $\eta_{\mathrm{N}}^{X}=\left(U_{X \mathrm{~N}}-U_{\mathrm{FeN}}\right)$ such as $X=\mathrm{Ni}, \mathrm{Co}, \mathrm{W}$ etc. listed in Table 1. Table 2 shows that the calculated results for $\varepsilon_{\mathrm{N}}^{X}$ agree with the measured values [16]. Ueno et al. [17] have also calculated $\varepsilon_{\mathrm{N}}^{X}$ using Miedema's semi-empirical method on the basis of the pseudopotential formalism coupled with Gibbs energy of the hard sphere system. They did not, however, refer to the relationship between $\eta_{N}^{X}$ and $\sigma_{\mathrm{N}}^{X}$.

\section{Concluding Remarks}

The consideration of the free volumes of the solute elements leads to the thermodynamic relationship between $\eta_{\mathrm{N}}^{X}$ and $\varepsilon_{\mathrm{N}}^{X}$ and between $\eta_{\mathrm{N}}^{X}$ and $\sigma_{\mathrm{N}}^{X}$ in liquid iron-nitrogen ternary alloys as well as in the metallic systems [6]. The free volume, strictly the displacement of the atoms from their equilibrium positions [7], is considered to be a main factor determining the excess entropy term of the infinitely dilute solutions.

Table 2. Calculated results for $\eta_{N}^{X}, \sigma_{N}^{X}$ and $\varepsilon_{N}^{X}$ with measured $\varepsilon_{N}^{X}$ at $1873 \mathrm{~K}$ in liquid iron-nitrogen based ternary alloys.

\begin{tabular}{|c|c|c|c|c|c|c|}
\hline \multirow[t]{2}{*}{ Elements } & \multirow[t]{2}{*}{$\stackrel{\eta_{N}^{X}}{\mathrm{~kJ}_{\mathrm{mol}}^{-1}}$} & \multirow[t]{2}{*}{$\begin{array}{l}\text { 1st term } \\
\text { in } \sigma_{N}^{X}\end{array}$} & \multicolumn{2}{|l|}{$\begin{array}{l}\text { 2nd term } \\
\text { in } \sigma_{\mathrm{N}}^{X}\end{array}$} & \multicolumn{2}{|c|}{$(1873 \mathrm{~K})$} \\
\hline & & & $/ \mathrm{J} \mathrm{K}^{-1} \mathrm{~mol}^{-1}$ & & calc. & exp. "i) \\
\hline $\begin{array}{l}\mathrm{Co} \\
\mathrm{Cr} \\
\mathrm{Mn} \\
\mathrm{Mo} \\
\mathrm{Ni} \\
\mathrm{W}\end{array}$ & $\begin{array}{r}44 \\
-122 \\
-114 \\
-183 \\
75 \\
-202\end{array}$ & $\begin{array}{r}-0.3 \\
0.1 \\
0.2 \\
1.3 \\
-0.3 \\
1.4\end{array}$ & $\begin{array}{r}11.5 \\
-31.5 \\
-29.6 \\
-47.4 \\
19.4 \\
-52.4\end{array}$ & $\begin{array}{r}11.2 \\
-31.4 \\
-29.4 \\
-46.1 \\
19.1 \\
-51.0\end{array}$ & $\begin{array}{r}1.5 \\
-4.0 \\
-3.8 \\
-6.2 \\
2.5 \\
-6.8\end{array}$ & $\begin{array}{r}2.9 \\
-9.8 \\
-4.5 \\
-5.1 \\
1.6 \\
-3.8 \mathrm{~b})\end{array}$ \\
\hline
\end{tabular}

a) The values of $\varepsilon_{\mathrm{N}}^{X}$ are given as $\mathrm{e}_{\mathrm{N}}^{X}=\left(\partial \ln f_{\mathrm{N}}^{X} / \partial[\mathrm{wt} \% X]\right)$ in Ref. [16]. $\varepsilon_{\mathrm{N}}^{X}$ has been transformed from $\mathrm{e}_{\mathrm{N}}^{X}$ by the following relation [16] $\varepsilon_{\mathrm{N}}^{X}=\frac{M_{X}}{55.85}\left(\frac{\mathrm{e}_{\mathrm{N}}^{X}}{0.00434}-1\right)+1$

where $M_{X} / \mathrm{g} \mathrm{mol}^{-1}$ is the atomic weight of element $X$.

b) $(1879 \mathrm{~K})$
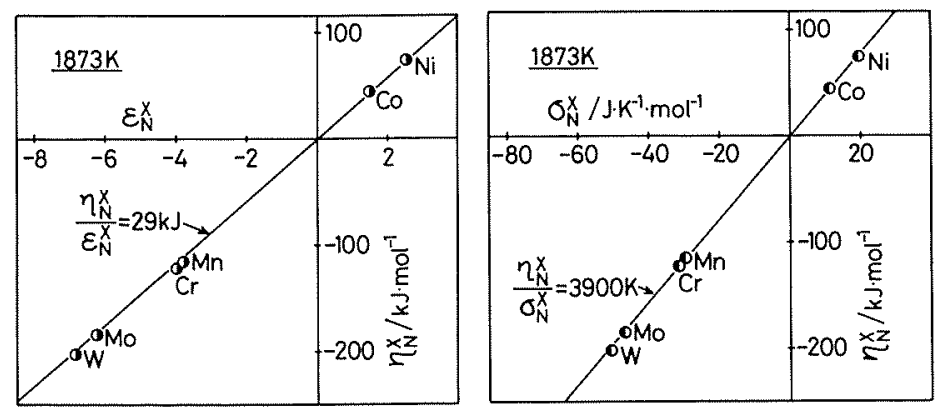

Fig. 2 (left). Relationship between $\eta_{N}^{X}$ and $\varepsilon_{N}^{X}$ at $1873 \mathrm{~K}$ in liquid iron-nitrogen based ternary alloys.

Fig. 3 (right). Relationship between $\eta_{N}^{X}$ and $\sigma_{N}^{X}$ at $1873 \mathrm{~K}$ in liquid iron-nitrogen based ternary alloys. 


\section{Literature}

1. Tanaka, T.; Gokcen, N. A.; Morita, Z.: Z. Metallkd. 81 (1990) $49-54$.

2. Tanaka, T.; Gokcen, N. A.; Morita, Z.: Z. Metallkd. 81 (1990) $349-353$.

3. Tanaka, T.; Gokcen, N. A.; Morita, Z.; Spencer, P. J.: Anales de Fisica-Ser. B. 86 (1990) 104-107.

4. Tanaka, T.; Gokcen, N. A.; Neuschütz, D.; Spencer, P. J.; Morita, $Z$.: Steel Research 62 (1991) 385-389.

5. Tanaka, T.; Imai, N.: Kiyose, A.; Iida, T.; Morita, Z.: Z. Metallkd. 82 (1991) 836-840.

6. Tanaka, T.; Gokcen, N. A.; Spencer, P. J.; Morita, Z.; Iida, T.: Z. Metallkd. 84 (1993) 100-105.

7. Tanaka, T.: Gokcen, N. A.; Morita, Z.; Iida, T.: Z. Metallkd. 84 (1993) 192-200.

8. Richardson, F. D.: Physical Chemistry of Melts in Metallurgy, Vol. 1, Academic Press, London (1974) 186-187.

9. Chipman, J.; Corrigan, D. A.: in: G. R. Fitterer (ed.), Applications of Fundamental Thermodynamics to Metallurgical Processes, Gordon and Breach, New York (1967) 23.
10. Tsu, Y.; Saito, T.: Trans. Jpn. Inst. Metals 14 (1973) $339_{-}$ 346.

11. Foo, E.-H.; Lupis, C. H. P.: Acta metall. 21 (1973) 14091430 .

12. de Boer, F. R.; Boom, R.; Mattens, W. C. M.; Miedena, A. R.; Niessen, A. K.: Cohesion in Metals, North-Holland, Amsterdam (1988).

13. Iida, T.; Guthrie, R. I. L.: The Physical Properties of Liquid Metals, Clarendon Press, Oxford (1988) 6, 100

14. Miedema, A. R.; de Chatel, P. F.; de Boer, F. R.: Physica $100 B$ (1980) $1-28$.

15. Bouten, P. C. P.; Miedema, A. R.: J. Less-Common Met. 65 (1979) $217-228$.

16. Steelmaking Data Sourcebook, The Japan Society for the Promotion of Science, The 19 th Committee on Steelmaking, Gordon and Breach, New York (1988) 273.

17. Ueno, S.; Waseda, Y.; Jacob, K. T.; Tamaki, S.: Steel Research 59 (1988) 474-483.

(Received December 9, 1993) 